\title{
Effect of Addition of HYPR and CABP on the Physiochemical and Mechanical Properties of Cement Pastes
}

\author{
Abdel Fattah A. Qaraman ${ }^{1}$, Wafaa S. Hegazy ${ }^{2}$, Faten Z. Mahmoud ${ }^{3}$, Maha R. mohamed $^{4}$ \\ ${ }^{1}$ Scientific Research Department, Israa University, Gaza, Palestine \\ ${ }^{2,3,4}$ Chemistry Department, Women College, Ain Shams University, Cairo, Egypt
}

\begin{abstract}
The lightweight aerated concrete, mortar and paste is recently acceptable for use in civil construction purposes as a result of their peculiar features such as heat-insulating, sound absorption, low self-weight and self-compacting features, hence their high workability, this features depend on their content of air. But their major demerits are its difficulty of high strength development when compared with normal ones. This paper studies the parameters leads to produce a sustainable aerated paste by choosing a suitable airentraining agent which entrain wide range of air with minimum lose in strength. To reach this goal a comparative study is carried out between the effect of adding different percentages of each of the cationic surfactant alkyl dimethyl hydroxyl ethyl ammonium chloride (HYBR) and the amphoteric surfactant cocamido propyl betaine (CAPB) to some Portland cement pastes. The influence of the different surfactant concentrations and the mixing times on the air content of the pastes and accordingly the bulk density, compressive strength and microstructure of the hardened cement specimens is discussed. The results demonstrate the preference of using CAPB over HYBR because its ability to give a wide range of air dosage and its ability to improve the compressive strength.
\end{abstract}

Keywords: air-entraining agent, density, compressive strength, XRD, HYPR, CABP, surfactant.

\section{Introduction}

Air entrainment is the process whereby many small air bubbles are incorporated into cement paste and become part of the matrix that binds. Rosen (2004) reported that formed air bubbles in cement paste are unstable and have a limited lifetime. Air entrainment may be accomplished by the use of an air-entraining agent (AEA). Nearly all modern day air entraining agents are part of a chemical group called surfactants (Algurnon, 2013). Surfactants are used to entrain air bubbles and stabilized them in the fresh cement pastes. Lea (1971) suggested that air-entraining surfactants operate at the air-water and the solid-water interface, as shown in Figure (1). At the air-water interface, the agent helps by reducing surface tension, which promotes dispersion and bubble formation. Dodson (1990) demonstrated that absorbed surfactants molecules at the surface of the bubble form a film, with their polar heads in the water phase. If the molecule is charged, the bubble acquires this charge. The electrostatic repulsion keeps bubbles separated and prevents coalescence.

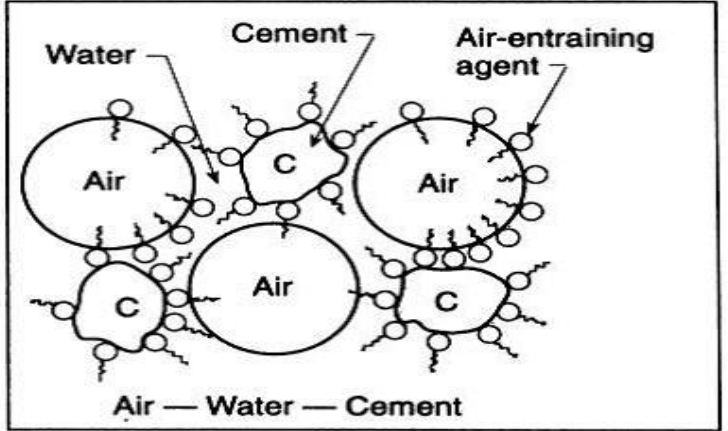

Figure 1: Interaction between air bubbles and cement particles.
It is well known that the pore structure of the hardened cement pastes strongly influence its physical properties. The presence of the air-entraining agent not only improves workability, but also enhances its freeze-thaw resistance (Hewlett, 2004). Du and Folliard (2005) noted that there is a minimum dosage of air entraining agent required to entrain air in the cement paste. Leslie and Qingye (2004) concluded that the addition of air-entraining agent increased the air content up to a saturation level, above which no further increase in air content was observed. Algurnon, (2013) stated that entrained air is influenced by a number of factors. Examples of such as factors include the duration of mixing, the nature and the concentration of the surfactants used as air-entraining agents. Concerning the mixing time, Patrick and donL (1968) reported that duration of the stirring affect the air void system in such a way as to cause an increase in the air content and the specific surface area of the voids as mixing time increases. Also Yang (2012) concluded that mixing longer time can entrain more air in fresh cement paste by applying more work on the paste.

The objective of this work is to study the effect of the mixing time, the nature and the concentration of two different surfactants HYBR and CAPB on the air content of cement paste and accordingly on the bulk density and the compressive strength of cement specimens. Also the microstructure of the hardened cement paste samples is examined using X-ray diffraction and SEM analyses. 


\section{Experimental}

\subsection{Materials}

- Portland cement of mark CEM I 52.5N obtained from ElArish cement factory. Its chemical composition is given in Table (1).

- Alkyl dimethyl hydroxyl ethyl ammonium chloride (HYBR) supplied from Clariant and cocamido propyl betaine (CAPB) supplied from Merck, both of surfactants are used as obtained.

Table 1: Chemical composition of the used ordinary Portland cement (OPC)

\begin{tabular}{|c|c|}
\hline Oxide (\%) & OPC \\
\hline $\mathrm{SiO}_{\mathbf{2}}$ & 22.12 \\
\hline $\mathbf{A l}_{\mathbf{2}} \mathbf{O}_{\mathbf{3}}$ & 5.56 \\
\hline $\mathrm{Fe}_{\mathbf{2}} \mathbf{O}_{\mathbf{3}}$ & 3.69 \\
\hline $\mathrm{CaO}^{\mathbf{O}}$ & 62.87 \\
\hline $\mathbf{N a}_{\mathbf{2}} \mathbf{O}$ & 0.26 \\
\hline $\mathbf{K}_{\mathbf{2}} \mathbf{O}$ & 0.11 \\
\hline $\mathbf{C l}^{-}$ & 0.02 \\
\hline $\mathbf{M g O}_{\mathbf{S O}}$ & 2.36 \\
\hline Free CaO & 0.91 \\
\hline Ignition LoSS & 0.92 \\
\hline
\end{tabular}

\subsection{Techniques and Instrumentation}

\subsubsection{Paste Preparation}

The cement specimens are prepared by dissolving different concentrations of each of the two surfactants mentioned above in $650 \mathrm{~g} \mathrm{H}_{2} \mathrm{O}$ then adding to $1500 \mathrm{~g}$ cement. The water to cement ratio (W/C is 0.43 as recommended (Carmel et al., 2003). The percentages of the surfactants used range from 0.005 to $0.080 \%$ by weight of cement.

The mixing is carried out under continuous and vigorous stirring for about three minutes (Carmel et al., 2003). After complete mixing the resulted pastes is poured into $(12 \times 4 \times 4$ $\mathrm{cm}^{3}$ ) moulds. The moulds are kept at about $100 \%$ relative humidity at room temperature for one day. The hardened cement pastes are then removed from the moulds after they attained the final setting and cured under water for the rest of the hydration ages (up to 360 days).

\subsubsection{Compressive Strength}

Three specimens of each mix at different hydration times (3, 7, 28, 90 and 360 days) are used for examination the compressive strength of the pastes. The mean value of the three specimens at each hydration age is considered as the determined compressive strength. The strength test machine used is of point load taster (20063 cemasco S/N-Controls) type, Milano-Italy.

\subsubsection{Stopping of Hydration}

This is performed after doing the compressive strength test by taking about $10 \mathrm{~g}$ of the crushed hardened pastes and putting into a beaker containing $100 \mathrm{ml}$ of acetone/ethyl alcohol (1:1 by volume) to stop the hydration process. The mixture is stirred for $0.5 \mathrm{hr}$. The residue is filtered off, washed with ethanol and dried at $50^{\circ} \mathrm{C}$ for about $24 \mathrm{hrs}$. The dried samples are then stored in a desiccator for the following physico-chemical analysis.

\subsection{Determination of the bulk density of the cement pastes:}

The bulk density is determined by measuring the weight of the sample in air and under water. The density is then calculated as mentioned in (ASTM Standard C 138-08 2008).

\subsubsection{Determination of the air entrained in the cement} pastes:

The percent of air entrained in pastes was determined by the difference in weight of a hardened cement paste in absence and in presence of surfactants by the equation (Carmel et al., 2003):

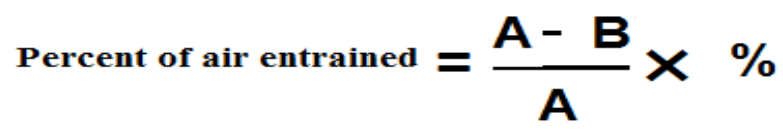

Where: A: The weight of hardened cement paste in absence of surfactant.

$\mathrm{B}$ : The weight of hardened cement paste in presence of surfactant.

\subsubsection{X-Ray Diffraction analysis (XRD):}

XRD patterns of the samples are recorded by using a Philips X Pert MPD diffractometer using copper target with nickel filter under working conditions of 40 kilo volts and 20 milliampers.

\subsubsection{Scanning Electron Microscopic measurements:}

(SEM)

The morphology and microstructure of the dried hydrated samples are studied using JEOL JXA 840 A electron Probe micro analyzer SEM. The specimens are coated with a thin film of gold under a vacuum evaporator with cathode rays then analyzed.

\section{Results and Discussion}

3.1 Effect of the presence of surfactants on the air content of the cement paste

Air content is the controlling factor which affects other aspects of the cement paste (i.e. density, compressive strength and workability). On adding an air entraining surfactant to cement pastes, its molecules are inserted between adjacent molecules at the water surface; the mutual attraction between the separated water molecules is reduced. Lowering the surface tension stabilizes the bubbles against mechanical deformation and rupture, making it easier for bubbles to be formed.

The values of the air content entrained in Portland cement pastes hydrated for 90 days in presence of different percentages of HYBR and CAPB are determined. It should be mentioned that the content of air entrained in cement pastes show a slight change at the different hydration ages (from 3 up to 90 days). However, the air content exhibits the best value at 90 days of hydration. The values of the air content in 


\section{International Journal of Science and Research (IJSR) \\ ISSN (Online): 2319-7064}

Index Copernicus Value (2013): 6.14 | Impact Factor (2014): 5.611

Portland cement pastes in presence of different percentages of HYBR and CAPB are given in Table (2). The results show a gradual increase in the air content with increasing surfactant concentration and reaches its maximum value at the concentration of $0.06 \%$ and $0.08 \%$ for HYBR and CAPB respectively.

Table 2: comparison between the air entrained by the HYBR and CAPB at 90 days

\begin{tabular}{|c|c|c|c|c|}
\hline \multirow{2}{*}{ Surfactant conc. } & 0.005 & 0.020 & 0.060 & 0.080 \\
\cline { 2 - 5 } & \multicolumn{4}{|c|}{$\%$ of air entrained } \\
\hline \% ) Surfactant & 3.04 & 9.60 & 17.87 & 14.08 \\
\hline HYBR & 7.90 & 22.10 & 35.80 & 38.70 \\
\hline CABP &
\end{tabular}

Both HYBR and CAPB have positive quaternary nitrogen which enhance the desperation of air bubbles and cement grains, the CAPB is amphoteric surfactant so it has remain negative charge which lowering the surface tension and stabilizes the bubbles against mechanical deformation and rupture and also makes it easier for bubbles to be formed, while the efficiency of HYBR as an AEA is supposed to be due to the probable formation of hydrogen bonding between the HYBR hydroxyl group and the oxygen atoms in the silica network (CSH) this may explain the efficiency of CAPB over HYBR as air entraining agent. From the data obtained and discussed in this paper and previous studies (Chatterji et al., 1992, and 2000 Myers,2006), it can be concluded that the efficiency of a surfactant as an air entraining agent in cement media depends on three main factors: (1) The sensitivity of the surfactant to water hardness or $\mathrm{pH}$ changes. The metal ions (e.g., $\mathrm{Ca}^{+2}$ and $\mathrm{Mg}^{+2}$ ) present in the medium may compete with other metal ions present in the structure of the surfactant this may affect the amount of the free surfactant available for the desired purpose and hence its efficiency. (2) The mechanism of interaction between the surfactant and the cement grains surface (the ionic attraction which is stronger than hydrogen bonding), this determines the ability of the surfactant to stabilize the formed air bubbles. (3) The electrostatic repulsion between similar charges which keeps bubbles and cement grains separated, this leads to media expansion (dispersion action).

\subsection{Effect of the presence of surfactants on the bulk} density of the cement paste:

The density of cement pastes is directly affected by the air content, they are inversely proportional to each other. The determined density of the hardened control specimen (zero surfactant concentration) and those of the specimens containing HYBR and CAPB surfactants after 90 days of hydration are shown in Table (3). The results showed that density decrease with increasing concentration, and reach its minimum at the concentration $0.06 \%$ wt and $0.08 \%$ wt of HYBR and CAPB respectively. It is found that, the density decreases by about $0.3 \mathrm{~g} / \mathrm{cm}^{3}$ when the air content is increased by about $14 \%$.
Table 3: The density $\left(\mathrm{g} / \mathrm{cm}^{3}\right)$ of hardened cement paste in presence of HYBR and CAPB surfactant at 90 days

\begin{tabular}{|l|l|l|l|l|l|}
\hline \multirow{2}{*}{$\begin{array}{r}\text { Surfactant Conc. } \\
\text { (wt \%) }\end{array}$} & 0.00 & 0.005 & 0.02 & 0.06 & 0.08 \\
\cline { 2 - 6 } & & & \multicolumn{5}{|c|}{$p\left(\mathrm{~g} / \mathrm{cm}^{3}\right)$} \\
\hline HYBR & 2.00 & 1.92 & 1.73 & 1.57 & 1.65 \\
\hline CAPB & 2.00 & 1.87 & 1.57 & 1.37 & 1.35 \\
\hline
\end{tabular}

3.3 Effect of the mixing time on the air content of the hardened cement paste in absence and presence of surfactants:

Mixing time plays an important role in controlling the air content in the cement pastes. The effect of changing the mixing intervals from 3 to 5,6 and 8 minutes is studied in absence and presence of the surfactants at $0.02 \%$ concentration after 90 days of hydration. It is found that changing the mixing time has no effect on the control pastes (without adding surfactant). Similar finding are reported in the literature (Powers 1968, Rosen 2004 and Algurnon 2013). It is supposed that in absence of an AEA, consolidation of the cement pastes will cause most of the air bubbles to make their way to the surface and burst.

However, the results obtained in presence of the surfactants (Table 4) show that the air entrained content increases gradually with increasing the mixing time intervals. This increasing has great effect on the HYBR mixes which give the impression that the dispersion action of HYBR is greater than CAPB.

This result is in a good agreement with previous studies reported by Bruere (1955) and Yang (2012). It is reported that the duration of stirring affects the air void system in such a way as to cause an increase in the air content. The specific surface area of the voids also increases as mixing time increases. Where, during prolonged mixing at a constant speed, air content increases rapidly at first and then slowly approaches an upper limit.

Table 4: The effect of mixing time on the percent of air entrained by HYBR and CAPB surfactants at the concentration $(0.02 \%)$

\begin{tabular}{|c|c|c|c|c|}
\hline Mixing time (min.) & 3 & 5 & 6 & 8 \\
\hline \% of air (HYBR) & 9.60 & 18.50 & 19.95 & 24.50 \\
\hline \% of air (CAPB) & 22.10 & 24.00 & 27.50 & 30.50 \\
\hline
\end{tabular}

\subsection{Effect of surfactants on the compressive strength of} the hardened cement paste

Compressive strength of hardened cement is an important criterion specified in the design of lightweight cement pastes and should be considered equally important as density (Algurnon, 2013). The properties of these pastes are time dependent; therefore, any test method on the cement pastes should be performed at a certain hydration age. In this work, the determined values of the compressive strength of Portland cement pastes in absence and in presence of surfactants HYBR and CAPB, at different concentrations and different hydration ages are given in Table (5) and Table (6) respectively. Generally, all mixes show an increase in the 


\section{International Journal of Science and Research (IJSR) \\ ISSN (Online): 2319-7064}

Index Copernicus Value (2013): 6.14 | Impact Factor (2014): 5.611

values of the compressive strength with increasing hydration time, this increase believed to be due to progress of the cement hydration with time.

Table 5: The compressive strength of hardened cement pastes containing HYPR at 3 ,7, 28, 90 and 360 days..

\begin{tabular}{|l|l|l|l|l|l|}
\hline \multirow{2}{*}{$\begin{array}{l}\text { Surf. Hyd. Time } \\
\text { Con. (wt\%) }\end{array}$} & 3days & 7 days & 28days & 90 days & 360 days \\
\cline { 2 - 6 } & \multicolumn{5}{|c|}{ compressive strength $\left(\mathrm{N} / \mathrm{mm}^{2}\right)$} \\
\hline 0.000 & 40.42 & 50.38 & 68.99 & 72.70 & 104.00 \\
\hline 0.005 & 48.00 & 51.41 & 66.52 & 70.19 & 98.00 \\
\hline 0.020 & 36.76 & 37.44 & 43.41 & 52.80 & 78.00 \\
\hline 0.060 & 25.25 & 26.07 & 31.52 & 37.42 & 53.00 \\
\hline 0.080 & 27.13 & 27.89 & 32.23 & 41.74 & 57.10 \\
\hline
\end{tabular}

Table 6: The compressive strength of hardened cement pastes containing CABP at 3, 7, 28, 90 and 360 days

\begin{tabular}{|c|c|c|c|c|c|}
\hline \multirow{2}{*}{$\begin{array}{l}\text { Surf. Hyd. time } \\
\text { Con. (wt \%) }\end{array}$} & 3 days & 7 days & 28 days & 90 days & 360 days \\
\cline { 2 - 6 } & \multicolumn{5}{|c|}{ compressive strength (N/mm² } \\
\hline 0 & 40.42 & 50.38 & 68.99 & 72.7 & 104 \\
\hline 0.005 & 31.14 & 42.78 & 52.28 & 54.73 & 82 \\
\hline 0.02 & 18.61 & 23.74 & 23.34 & 36.58 & 49 \\
\hline 0.06 & 7.45 & 9.93 & 11.67 & 16.7 & 27 \\
\hline 0.08 & 7.2 & 8.4 & 10.04 & 15.6 & 25.4 \\
\hline
\end{tabular}

In all cases, the compressive strength decreases on increasing surfactants concentration at all hydration ages. This is expected as being due to the increasing percentages of entrained air which may affect the compressive strength values. Figure (2) demonstrates the preference of using CAPB, as example the CAPB specimen which have $22 \%$ air nearly give the same compressive strength of the HYBR specimen with $17.8 \%$ air content in addition to its ability to give a wide range of entrained air.

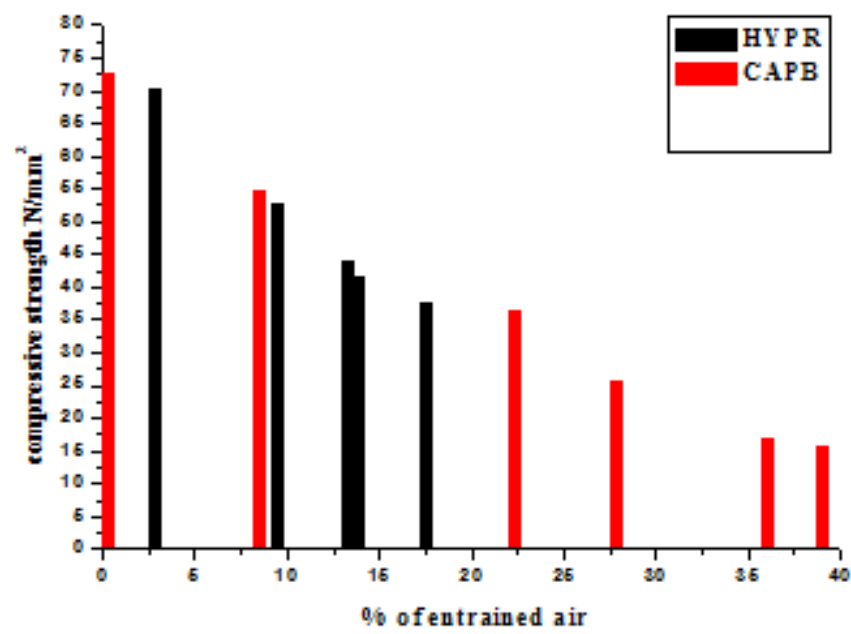

Figure 2: The effect of air entrained by HYBR and CAPB surfactants on the compressive strength of hardened cement paste at 90 days.

3.5 The effect of HYBR surfactant on the phase composition of the hardened cement paste

The rates of change in physical and chemical properties of Portland cement pastes depend upon the rates of hydration of the components in cement. Both $\mathrm{C}_{3} \mathrm{~S}$ (alite phase) and $\beta-\mathrm{C}_{2} \mathrm{~S}$ (belite phase) react with water to form calcium silicate hydrate $(\mathrm{C}-\mathrm{S}-\mathrm{H})$ and calcium hydroxide $(\mathrm{CH})$. The C-S-H provides most of the strength developed by Portland cement, $\mathrm{C}_{3} \mathrm{~S}$ hydration occurs more rapidly than $\mathrm{C}_{2} \mathrm{~S}$ hydration. Therefore, $\mathrm{C}_{3} \mathrm{~S}$ provides most of the early age strength while $\mathrm{C}_{2} \mathrm{~S}$ contributes mostly to the later age strength [Gartner et al., 2002].

The phase composition of the various hardened Portland cement pastes in absence and presence of surfactants HYBR and CAPB is examined at two hydration ages ( 7 days to examine the early age hydration $\& 360$ days to examine the later age hydration) with 0.02 and 0.08 concentrations using $\mathrm{X}$-ray diffraction technique. The hydration of the cement components results are the conversion of $\mathrm{C}_{3} \mathrm{~S}$ and $\beta-\mathrm{C}_{2} \mathrm{~S}$ into the hydration products, Calcium silicate hydrate $(\mathrm{CSH})$ and calcium hydroxide $(\mathrm{CH})$ as shown in Figure (3) and Figure (4). Accordingly, the intensity of the characteristic peaks of the reactants such as alite and belite phases decreases with increasing the hydration age.

At 7 days, it is found that the intensity of the peaks characteristic of calcium silicate hydrate $(\mathrm{CSH})$, increases with adding the HYBR surfactant comparing with the blank at the same age while it can be noticed that the intensity of $\mathrm{CH}$ peaks in presence of CAPB is higher than those in blank. This indicates that both HYBR and CAPB accelerates the hydration of Portland cement paste in early ages.

After year the peaks characteristic of $\beta-C_{2} S$ (belite phase) disappear and completely converted to the hydration products, calcium silicate hydrate $(\mathrm{CSH})$ and calcium hydroxide $(\mathrm{CH})$, there is no difference in the blank and specimens in presence of both HYBR and CAPB

Hence, it can be concluded that both HYBR and CAPB enhance the hydration reaction in early age but after year they have no effect on the hydration reaction.

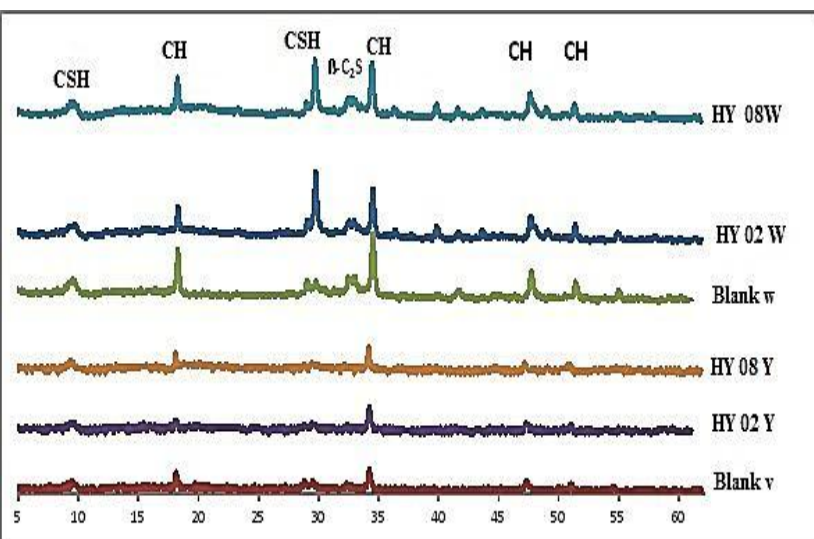

Figure 3: X-ray diffraction patterns of the control hardened cement paste and the hardened cement pastes with 0.02 and $0.08 \%$ HYBR at 7 days (W) and 360 days (Y) 


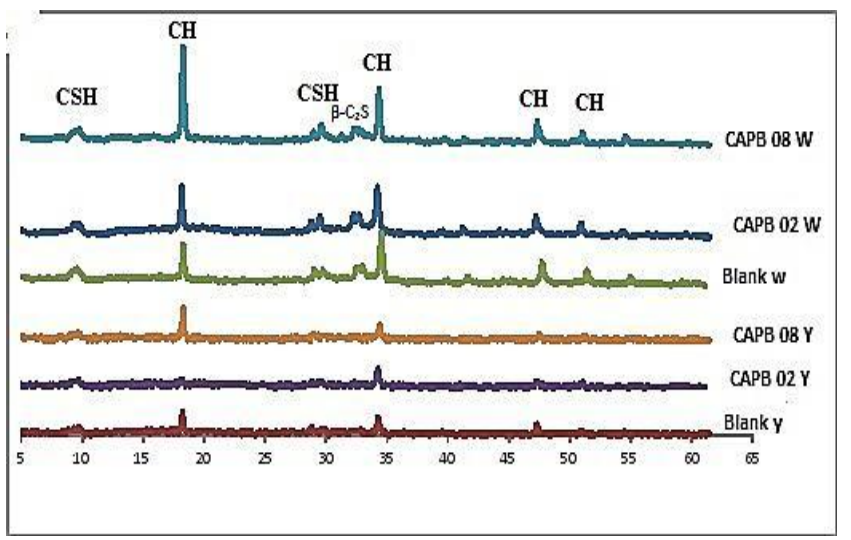

Figure 4: X-ray diffraction patterns of the control hardened cement paste and the hardened cement pastes with 0.02 and $0.08 \%$ CAPB at 7 days (W) and 360 days (Y).

\subsection{Microstructure and Morphology Investigations (SEM Analysis):}

The scanning electron microscope (SEM) is a powerful tool for imaging and chemical analysis in cement research. With a high resolution and a large depth of focus, it enables a detailed study of surface topography of the rough surfaces of e.g. the formed calcium silicate hydrate (C-S-H) and calcium hydroxide $(\mathrm{CH})$.

Scanning electron microscope (SEM) is used to examine the surface structure of hardened cement pastes, in absence and in presence of $0.08 \% \mathrm{CAPB}$ and $0.08 \%$ HYBR at the two hydration ages 7 and 360 days to examine the early and late ages of hydration.

Microscopic photos is illustrated in Figure 5 ( $a, b$ \& c). Figure (5-a) shows the hydration products formed in absence of surfactants. Calcium hydroxide appears as hexagonal plates beside fibrous CSH phase. Addition of HYBR, Figure (5-b) shows increase calcium hydroxide, the calcium hydroxide has a layered structure appearance beside $\mathrm{CSH}$ crystals.

Figure (5-c) shows the micrographs of the hardened Portland cement paste in presence of CAPB, a large Calcium hydroxide hexagonal plates beside $\mathrm{CSH}$ phase can be noticed.

Figure ( 6) (a, b, \& c) shows the micrographs of the hardened Portland cement pastes in absence of surfactants (blank) and in presence of $0.08 \%$ CAPB and $0.08 \%$ HYBR after 360 days hydration. It can be noticed that the hydration products have more compact structure composed of calcium silicate hydrates which explains the improvement in the strength after year for all mixes.

Microscopic examination shows that when HYBR is used, a large air voids $(124.2 \mu \mathrm{m})$ is appeared, While CAPB produces consistent bubble structure with a uniform small air voids system $(85.7 \mu \mathrm{m})$ which as a result improves strength.

From the above results, it can be concluded that both of HYBR and CAPB accelerate the hydration reaction which enhance the findings of a great deal of the X-Ray results, but
CAPB is prefer than HYBR as air-entraining agent because it produce a uniform air void system which enhance the compressive strength results.

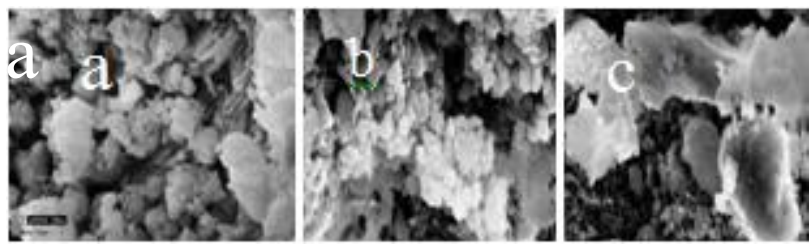

Figure 5: SEM of hardened cement pastes after 7 days hydration $(X=5000)$. a) Without surfactant b) With $0.08 \%$ HYBR c) with $0.08 \%$ CAPB
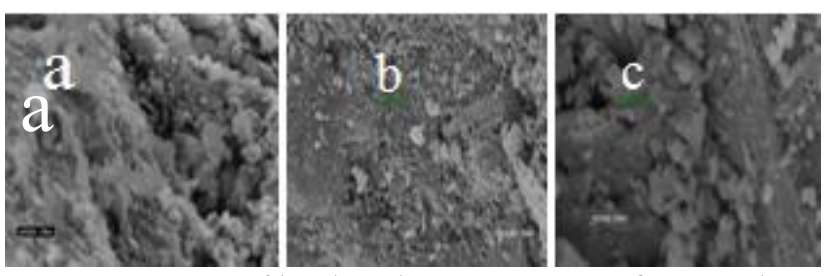

Figure 6: SEM of hardened cement pastes after 360 days hydration $(X=5000)$. a) Without surfactant b) With $0.08 \%$ CAPB c) With $0.08 \%$ HYBR

\section{Conclusion}

The comparison study between HYBR cationic surfactants and CAPB amphoteric surfactants demonstrate the preference of using CAPB over HYBR when we want to entrain a high dosage of air because it improves the compressive strength and can entrain a wide range of air, on other hand the HYBR has a good dispersion action than CAPB this appears from the mixing action.

\section{References}

[1] Algurnon, S. R., (2013) Structural lightweight aerated concrete, Master Thesis, Stellenbosch University, South Africa.

[2] ASTM Standard C138-08, (2008) Standard Test Method for Density (Unit Weight), Yield and air content (Gravimetric) of hardened cement pastes, American Society of Testing and Materials, PA.

[3] Bruere, G. M., (1955) Air Entrainment in Fresh Concrete with PFA, Journal of American Concrete Institute, 26(9): 905 - 920.

[4] Carmel J., Thi C. T., Thuc S. N., Russell H. and Monique P., (2003) Investigation of physico-chemical aspects of air entrainment in cementitious systems $7^{\text {th }}$ CANMET/ACI, International Conference on Super Plasticizers and other Chemical Admixtures in Concrete, Berlin, Germany, ACI SP-217, 595-619.

[5] Chatterji ,S. and Kawamura , M., (1992) Electrical double layer, ion transport and reactions in hardened cement pastes, Cement and Concrete Research, 5 (22), 774-782.

[6] Copeland, L. E., Kantro, D. L., and George V., (1960) Chemistry of Hydration of Portland Cement, National Bureau of Standards Monograph, 43(I): 429-465.

[7] Dodson, V.H., (1990) Concrete Admixtures, New York, Van Nostrand Reinhold, 129-211. 
[8] Du, L. and Folliard, K. J., (2005) Mechanisms of air entrainment in concrete, Cement and Concrete Research, (35): 1463-1471.

[9] Gartner, E., Corr, D. J., Lebourgeois, J., Monteiro, P. J. M. and Bastacky, S. J., (2002) Air Void Morphology in Fresh Cement Pastes, Cement and Concrete Research, (32): $1025-1031$.

[10] Hewlett, P., (2004) Lea's Chemistry of cement and concrete, Elsevier Science \& Technology Books Pub.

[11]Lea, F. M., (1971) "Cement Research: Retrospect and Prospect", Proceeding International Symposium on the Chemistry of Cement, Washington D.C., 5-8.

[12]Leslie J.S. and Qingye J., (2004) Effect of Air Entraining on Rheology, ACI Materials Journal, 11-12.

[13] Myers, D., ,(2006) Surfactants science and technology, 3rd edition, New York, John Wiley \& Sons, pp. 48-82.

[14] Patrick, H., and donL, I., (1968) Review of literature on air-entrained concrete, Texas University, USA.

[15] Powers, T. C., (1968) The properties of fresh concrete, New York, John Wiley \& Sons, 664.

[16]Rosen, M. J., (2004) Surfactants and Interfacial Phenomena, $3^{\text {rd }}$ ed., New Jersey, John Wiley \& Sons, 464.

[17] Yang qi, (2012) Stability of air bubbles in fresh concrete, Master Thesis, Chalmers University of Technology, Sweden.

\section{Author Profile}

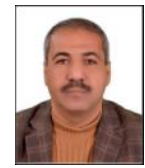

Abdel Fattah A. Qaraman received the B.S. and M.S. degrees in Chemistry from Bethlehem University in 1994 and Al-Azhar University in 2006, respectively. During 2012-2015, he follow his study in Ph.D. in inorganic chemistry at Ain Shams university. 19962014, he worked in Ministry of education, from 2014 until now he occupied the head of UC department in Israa University. 